\title{
Discussion: Dynamic properties of large aggregate concrete under triaxial loading
}

\section{Linlin Shi}

School of Civil Engineering and Architecture, Changzhou Institute of

Technology, Changzhou, P.R. China; State Key Labor Coastal and Offshore Engineering, Dalian University of Technology, Dalian, P.R. China

\section{Licheng Wang}

State Key Labor Coastal and Offshore Engineering, Dalian University of Technology, Dalian, P.R. China

\section{Yupu Song}

State Key Labor Coastal and Offshore Engineering, Dalian University of Technology, Dalian, P.R. China

\section{Lu Shen}

State Key Labor Coastal and Offshore Engineering, Dalian University of Technology, Dalian, P.R. China

\section{José R. Martí-Vargas}

Professor, ICITECH, Institute of Concrete Science and Technology, Universitat Politècnica de València, Valencia, Spain

\section{Contribution by José R. Martí-Vargas}

Based on an experimental investigation, Shi et al. (2015) analysed the dynamic properties of large aggregate concrete under triaxial tension-compression-compression loading states. Strain rates ranging from $10^{-5}$ to $10^{-2} \mathrm{~s}^{-1}$ and seven stress ratios were combined to obtain stress-strain relationships, tensile strength $\left(\sigma_{1 \mathrm{f}}\right)$, critical strain $\left(\varepsilon_{1 \mathrm{f}}\right)$, secant modulus $\left(E_{\mathrm{sec} 1}\right)$ and failure modes. The authors should be complimented for producing this detailed paper of interest for the discusser, who would like to offer the following comments for the authors' consideration and response.

The authors state that $\sigma_{1 \mathrm{f}}$ increases almost linearly with the logarithmic increase of strain rate. This can be observed in Figure 5. However, it seems that there are some inconsistencies regarding the depicted values and the average values included in Table 2. By way of example, according to Table 2, $\sigma_{1 \mathrm{f}}$ is 1.25 MPa for $10^{-4} \mathrm{~s}^{-1}$ and $0 \cdot 3:-1:-1$, whereas a value about $1.20 \mathrm{MPa}$ is depicted in Figure 5. In general terms, the values of $\sigma_{1 \mathrm{f}}$ in Figure 5 are lower than the corresponding values in Table 2 .

The discusser agrees with the authors' conclusion that $\sigma_{1 \mathrm{f}}$ decreases as the absolute value of confined compressive stress increases. However, in the discusser's opinion, Figure 6(a) does not reflect the different compressive stress levels as all curves correspond to stress ratios with $\sigma_{2}=\sigma_{3}=-1$. Instead, the four stress ratios having $\sigma_{1}=0 \cdot 1$ could offer a better option as $\sigma_{2}$ ranges from $-0 \cdot 25$ to -1 , which refer to different confined compressive stress levels. As observed in Table 2 for each strain rate, $\sigma_{1 \mathrm{f}}$ decreases when $\left|\sigma_{2}\right|$ increases, more markedly between $\sigma_{2}=-0 \cdot 25$ and $\sigma_{2}=-0 \cdot 5$.

Regarding Figure 6(b), the authors detail that $\sigma_{3 \mathrm{f}}$ reduced as the absolute value of $\sigma_{2 \mathrm{f}}$ increased. However, the discusser notes that the four curves shown in Figure 6(b) correspond to the four stress ratios with $\sigma_{1}=0 \cdot 1$. For the same stress ratio, $\sigma_{3 \mathrm{f}}$ increases when $\sigma_{2 \mathrm{f}}$ increases, and there is not any reduction in $\sigma_{3 \mathrm{f}}$ based on $\sigma_{2 \mathrm{f}}$ : the specimens ruptured by one apparent tensile crack perpendicular to the direction of the applied tensile loading, and the curves directly reflect the fixed $\sigma_{3} / \sigma_{2}$ ratios.

The authors conclude that $\varepsilon_{1 \mathrm{f}}$ increases with an increase in confined compressive stress at the same strain rate. This is observed in Table 3. However, the discusser points out that there are some exceptions concerning the $0 \cdot 1:-1:-1$ stress ratio with respect to the $0 \cdot 1:-0 \cdot 75:-1$ stress ratio for strain rates of $10^{-4}, 10^{-3}$ and $10^{-2} \mathrm{~s}^{-1}$

Finally, the discusser notes that perhaps there are some errata and/or inconsistencies that may hinder understanding of the paper, as follows.

- 'Strain ratio' should be replaced with 'stress ratio' in Tables 2, 3 and 4.

- A 0.2:-1:-1 stress ratio should be detailed instead of $-1:-1: 0 \cdot 2$ in Figure 4.

- Figure 7 shows stresses $\sigma_{\text {su }}$ and $\sigma_{\text {ru }}$ instead of $\sigma_{3}$ and $\sigma_{1}$, respectively.

- The expression for tangential octahedral stress presents the same term twice.

- It seems that some of the values included in Table 5 should be corrected (e.g. values of $\sigma_{1 \mathrm{f}}$ for $0 \cdot 1:-0 \cdot 25:-1$ are equal to $1 \cdot 32,1.45$ and 1.68 , not to $1 \cdot 23,1.40$ and 1.63 , respectively).

\section{Authors' reply}

After checking Figure 5, it was found that these inconsistencies are caused by a printing error of the grid lines of the $y$-axis $\left(\sigma_{1 \mathrm{f}}\right.$-axis). The correct figure is given here as Figure 12.

With regard to the discusser's second point, there are two types of stress ratio that reflect the effect of compressive stress state on dynamic tensile strength. One type for the stress ratio $\sigma_{1}: \sigma_{2}: \sigma_{3}$ is $0 \cdot 1:-x:-1$, which means that $\sigma_{2}$ ranges from $-0 \cdot 25$ to -1 when $-\sigma_{1} / \sigma_{3}=0 \cdot 1$. Another type for the stress ratio 


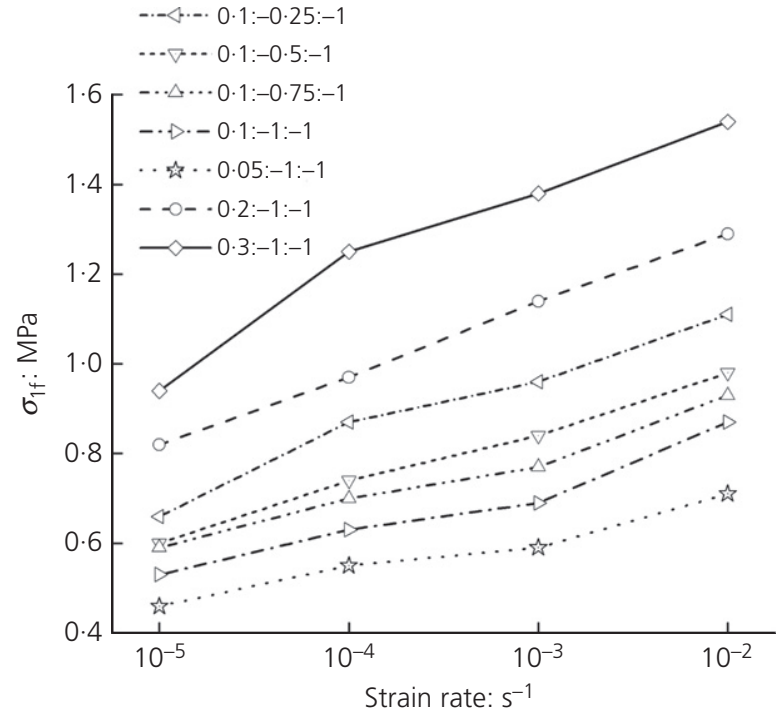

Figure 12. Influence of strain rate on $\sigma_{1 f}$

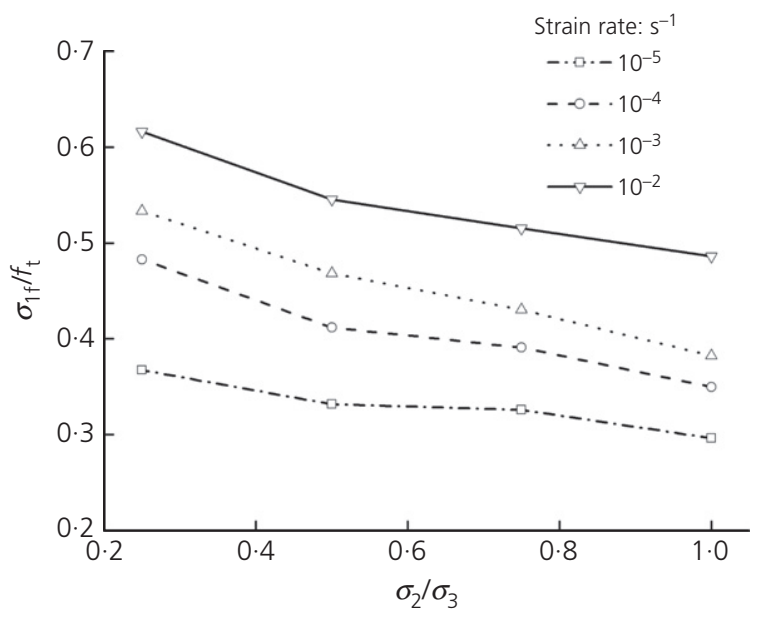

Figure 13. Effect of intermediate stress ratio $\sigma_{2} / \sigma_{3}$ on tensile strength $\sigma_{1 f}$ $\sigma_{1}: \sigma_{2}: \sigma_{3}$ is $x:-1:-1$, which means that $\sigma_{1}$ ranges from $0 \cdot 05$ to $0 \cdot 3$ when $\sigma_{2} / \sigma_{3}=1$. The purpose of the original work was to find the influencing effect of the intermediate stress $\sigma_{2}$ on $\sigma_{1 \mathrm{f}}$ and $\sigma_{3 \mathrm{f}}$. Obviously, $\sigma_{1 \mathrm{f}}$ reduces more apparently as the absolute values of both $\sigma_{2}$ and $\sigma_{3}$ increase than by only increasing the absolute value of $\sigma_{2}$. The intermediate stress ratio should be expressed as $\sigma_{2} / \sigma_{3}$, but in the published paper (page 288, line 1 of the left-hand column), it was written as $-\sigma_{1} / \sigma_{3},\left(\sigma_{2}=\sigma_{3}\right)$, which is wrong in this form. As suggested by the discusser, the tensile strength $\sigma_{1 \mathrm{f}}$ is plotted against the intermediate stress ratio $\sigma_{2} / \sigma_{3}$ for the case of $0 \cdot 1$ in Figure 13 .

As mentioned by the discusser, the curves in Figure 6(b) in the published paper directly reflect the fixed $\sigma_{2} / \sigma_{3}$ ratios. Actually, it is better to plot the curve between $-\sigma_{3}$ and $\sigma_{2} / \sigma_{3}$ in order to show the effect of intermediate stress $\sigma_{2}$ on the maximum compressive stress at failure, although the specimen was fractured by tensile cracking. It is important to study the compressive strength of concrete under the stress states of tension and compression in the construction of concrete dams. However, for the case of $\sigma_{1} / \sigma_{3}=0 \cdot 1,-\sigma_{3}$ is always 10 times $\sigma_{1}$, so the tendency between $-\sigma_{3}$ and $\sigma_{2} / \sigma_{3}$ is similar to that of $\sigma_{1 \mathrm{f}}-\sigma_{2} / \sigma_{3}$. In a similar way, in order to investigate the failure surface of concrete, the relationship of $\sigma_{2 \mathrm{f}}$ and $\sigma_{3 \mathrm{f}}$ with fixed $-\sigma_{1} / \sigma_{3}$ can also be shown as 0 (biaxial compression stress state), $0 \cdot 2,0 \cdot 3$ and so on.

The conclusions of the paper were summarised from experimental results obtained over a wide range of stress states. The authors considered the confined effect or increase of $\varepsilon_{1 \mathrm{f}}$ by increasing $\sigma_{3}$, which was shown in Figure 10 of the original paper. As mentioned by the discusser, with an increase in intermediate stress $\sigma_{2}, \varepsilon_{1 \mathrm{f}}$ does not increase linearly, especially when the stress ratio $\sigma_{2} / \sigma_{3}$ is increased from $0 \cdot 1:-0 \cdot 75:-1$ to $0 \cdot 1:-1:-1$; there is a reduction in $\varepsilon_{1 \mathrm{f}}$. It is worth noting that both increases and decreases in strain have been observed for concrete specimens under dynamic loading by different authors (Bischoff and Perry, 1991). In fact, for inherent heterogeneity and the large scatter of strain in concrete, more tests should be carried out.

Table 7. Increasing percentage of tensile strength and deformation with strain rate

\begin{tabular}{|c|c|c|c|c|c|c|c|c|c|}
\hline \multirow{2}{*}{$\begin{array}{l}\text { Stress, strain, } \\
\text { elastic modulus }\end{array}$} & \multirow{2}{*}{$\begin{array}{l}\text { Strain } \\
\text { rate: } s^{-1}\end{array}$} & \multicolumn{8}{|c|}{ Strain ratio } \\
\hline & & 1:0:0 (uniaxial T) & $0 \cdot 1:-0 \cdot 25:-1$ & $0 \cdot 1:-0 \cdot 5:-1$ & $0 \cdot 1:-0 \cdot 75:-1$ & $0 \cdot 1:-1:-1$ & $0 \cdot 05:-1:-1$ & $0 \cdot 2:-1:-1$ & $0 \cdot 3:-1:-1$ \\
\hline \multirow[t]{4}{*}{$\sigma_{1 f}$} & $10^{-5}$ & 1 & 1 & 1 & 1 & 1 & 1 & 1 & 1 \\
\hline & $10^{-4}$ & $1 \cdot 18$ & 1.32 & 1.23 & $1 \cdot 19$ & 1.19 & $1 \cdot 20$ & $1 \cdot 18$ & $1 \cdot 33$ \\
\hline & $10^{-3}$ & $1 \cdot 39$ & 1.45 & 1.40 & $1 \cdot 30$ & $1 \cdot 30$ & $1 \cdot 28$ & $1 \cdot 39$ & 1.47 \\
\hline & $10^{-2}$ & $1 \cdot 59$ & 1.68 & 1.63 & 1.58 & 1.64 & 1.54 & 1.57 & 1.64 \\
\hline \multirow[t]{4}{*}{$\varepsilon_{1 f}$} & $10^{-5}$ & 1 & 1 & 1 & 1 & 1 & 1 & 1 & 1 \\
\hline & $10^{-4}$ & $1 \cdot 10$ & 1.01 & 1.05 & 1.05 & 1.03 & 1.02 & 1.02 & 1.01 \\
\hline & $10^{-3}$ & $1 \cdot 15$ & 1.08 & 1.08 & 1.08 & $1 \cdot 04$ & 1.03 & 1.05 & 1.02 \\
\hline & $10^{-2}$ & $1 \cdot 17$ & 1.08 & 1.09 & 1.13 & 1.04 & 1.03 & 1.06 & 1.06 \\
\hline \multirow[t]{4}{*}{$E_{1}$} & $10^{-5}$ & 1 & 1 & 1 & 1 & 1 & 1 & 1 & 1 \\
\hline & $10^{-4}$ & $1 \cdot 08$ & $1 \cdot 33$ & $1 \cdot 12$ & $1 \cdot 13$ & $1 \cdot 20$ & $1 \cdot 19$ & $1 \cdot 11$ & $1 \cdot 32$ \\
\hline & $10^{-3}$ & $1 \cdot 15$ & 1.33 & 1.29 & 1.18 & 1.26 & 1.26 & 1.33 & 1.40 \\
\hline & $10^{-2}$ & $1 \cdot 30$ & 1.54 & 1.43 & $1 \cdot 36$ & 1.49 & 1.48 & 1.48 & 1.50 \\
\hline
\end{tabular}


The errors pointed out by the discusser exist. The authors appreciate the discusser's attentive work and respond as follows.
The values in Table 5 were checked and calculated again. Table 7 shows the corrected values in bold font.

\section{REFERENCES}

Bischoff PH and Perry SH (1991) Compressive behavior of concrete at high strain rates. Materials and Structures 24(6): 425-450.

Shi L, Wang L, Song Y and Shen L (2015) Dynamic properties of large aggregate concrete under triaxial loading. Magazine of Concrete Research 67(6): 282-293, http://dx.doi.org/10.1680/ macr.14.00225. 